\title{
Perbandingan Metode Weighted Moving Average dan Single Exponential Smoothing Angka Partisipasi Sekolah Wilayah Adat, Papua
}

\author{
Felix Reba $^{1 *}$, Alvian Sroyer ${ }^{2}$, Sara M. Yokhu ${ }^{3}$, Agustinus Langowuyo ${ }^{4}$ \\ email: felix.reba85@gmail.com
}

1,2,3,4 Matematika, Fakultas MIPA, Universitas Cenderawasih

\begin{abstract}
School Participation Rate (SPR), which is one of the indicators of successful education, includes the development or improvement of educational services in regions of Indonesia. Regarding the extent of each customary territory of Papua Province, there are very significant differences in SPR in the last 10 years, especially in 2010-2019. Some districts have experienced a drastic decline in their SPR in the last 4 years and some have fluctuating data. This study aims to compare the Weighted Moving Average (WMA) and Single Exponential Smoothing (SES) methods on SPR data at the elementary, junior high, senior high schools and equivalent levels in five customary territory of Papua Province. This study uses data on the percentage of SPR in 2010-2019 taken from the Central Statistics Agency (BPS) of Papua Province. Based on the results of Mean Absolute Percentage Error (MAPE), SES method is better than WMA. It means that the SES method is a suitable method for forecasting fluctuating SPR data. Thus, SES can be a reference method for the government for forecasting SPR in the coming year. If researchers use more data and more complex variables, it will require additional applications such as Matlab and POM QM.
\end{abstract}

Keywords: APS; WMA; SES; MAPE; Papuan customary territory.

\begin{abstract}
ABSTRAK
Angka Partisipasi Sekolah (APS) merupakan salah satu indikator keberhasilan pendidikan meliputi pengembangan atau pembangunan layanan pendidikan pada suatu wilayah di Indonesia. Akibat luasnya masing-masing wilayah adat Provinsi Papua, terdapat perbedaan APS yang sangat signifikan dalam 10 tahun terakhir, khususnya tahun 2010-2019. Ada kabupaten yang mengalami penurunan APS secara drastis dalam 4 tahun terakhir, ada juga kabupaten yang datanya berfluktuasi. Penelitian ini bertujuan untuk membandingkan metode Weighted Moving Average (WMA) dan Single Exponential Smoothing (SES) data APS jenjang SD, SMP, SMA dan Sederajat lima wilayah adat provinsi Papua. Data yang digunakan dalam penelitian ini adalah data persentase APS tahun 2010-2019 yang diambil dari Badan Pusat Statistik (BPS) Provinsi Papua. Berdasarkan hasil MAPE, metode SES lebih baik dibandingkan WMA. Artinya metode SES merupakan metode yang sesuai untuk peramalan data APS yang berfluktuasi. Sehingga SES dapat menjadi metode rujukan bagi pemerintah untuk peramalan APS ditahun yang akan datang. Apabila para peneliti menggunakan data yang lebih banyak serta variabel yang lebih kompleks, maka diperlukan tambahan aplikasi seperti: Matlab dan POM QM.
\end{abstract}

Kata kunci: APS; WMA; SES; MAPE; Wilayah Adat Papua. 


\section{PENDAHULUAN}

Salah satu aspek yang berperan penting dalam terciptanya sumber daya manusia yang berkualitas adalah pendidikan. Indikator keberhasilan pendidikan pada suatu wilayah disebut Angka Partisipasi Sekolah (APS) (Wahyuni et al., 2020). Menurut riset yang dilakukan oleh lembaga penelitian SMERU melalui program Research on Improve the Education System (RISE), diketahui bahwa APS di Indonesia pada akhir tahun ajaran 2020/2021, tren APS di semua jenjang pendidikan, mulai dari Pendidikan Anak Usia Dini (PAUD) hingga perguruan tinggi mengalami penurunan (Puti Yasmin, 2021). Provinsi Papua adalah salah satu dari beberapa Provinsi di Indonesia yang mengalami penurunan APS. Hal ini tidak lepas dari banyaknya wilayah adat di Papua yang belum memiliki akses Pendidikan yang memadai. Papua memiliki lima wilayah adat sedangkan Papua barat hanya memiliki dua wilayah adat. Lima wilayah adat Papua yakni Mamta, Saireri, Anim Ha, La Lago, dan Mee Pago (Yolanda, 2019). Akibat luasnya masing-masing wilayah adat, terdapat perbedaan APS yang sangat signifikan dalam 10 tahun terakhir, khususnya tahun 2010-2019. Ada Kabupaten yang mengalami penurunan APS secara drastis dalam 4 tahun terakhir, ada juga kabupaten yang datanya berfluktuasi (BPS, 2019).

Penelitian secara umum terkait APS telah dilakukan di beberapa wilayah di Indonesia seperti yang dilakukan oleh (Karini, 2018; Rahmatin \& Soejoto, 2017; Nurhanifa \& Pujiastuti, 2020). Sejauh ini belum ada penelitian khusus terkait APS pada lima wilayah adat di Papua. Juga penelitian sebelumnya masih menggunakan metode uji pengaruh untuk data berfluktuasi. Pada hal untuk data APS yang berfluktuasi biasanya digunakan metode Weighted Moving Average (WMA) dan Single Exponential
Smoothing (SES). Model ini mengasumsikan data berfluktuasi di sekitar nilai rata-rata yang tetap, tanpa mengikuti pola atau trend yang nantinya akan dijadikan patokan dalam melakukan perhitungan (Rachman, 2018).

Penelitian untuk data yang berfluktuasi seperti yang dilakukan oleh (Ardiana \& Loekito, 2018), dalam penelitian mereka merancang dan membangun Sistem Informasi berbasis web dengan metode WMA untuk proses peramalan persediaan barang. Selanjutnya (Rachman, 2018) melakukan penelitian dengan mengidentifikasi dan menganalisis hasil peramalan produksi garment dengan menggunakan metode peramalan SMA dan SES. Dalam dua metode peramalan di atas, digunakan Mean Square Error (MSE) untuk mengecek kelayakan metode dan hasil peramalan. Berdasarkan uraian diatas, penelitian ini bertujuan membandingkan metode WMA dan SES untuk menganalisis data APS jenjang SD, SMP, SMA dan Sederajat pada lima wilayah adat di Papua pada tahun 2010-2019. Hasil peramalan kemudian akan digunakan Mean Absolute Percentage Error (MAPE) untuk mengukur keakuratan metode.

Ada begitu banyak penelitian terkait perbandingan metode peramalan yang kemudian ditentukan kebaik metode menggunakan MAPE seperti yang dilakukan oleh (Rais et al., 2020; Hudaningsih et al., 2020; Asynari et al., 2020; Yudiarti \& Wira, 2019; Arnita, 2020). Namun dalam penelitian ini, perbandingan metode tidak hanya untuk mengatakan bahwa satu metode lebih unggul, tetapi peneliti dapat memiliki kemungkinan yang lebih besar untuk menemukan wawasan di setiap kasus dan mengetahui cara yang lebih efektif dalam menangani kasus APS. Hal lainnya adalah, khususnya wilayah Papua masih banyak kasus dengan data yang berfluktuasi, namun selama ini masih di 
analisis dengan metode-metode konvensional, sehingga kedua metode ini masih merupakan hal yang baru yang perlu diperkenalkan kepada dinas Pendidikan Provinsi Papua.

\section{METODE}

Langkah analisis dalam penelitian ini adalah : Menyiapkan data APS lima wilayah adat yang diwakili oleh lima kabupaten, melakukan uji stasioner, meramal APS dengan metode Weighted Moving Average, peramalan juga dilakukan dengan metode Single Exponential Smoothing dan yang terakhir membandingkan kedua metode dengan MAPE. Secara ringkas dijelaskan sebagai berikut:

\section{A. Menyiapkan Data}

Menyiapkan data disini menyakut pemilihan beberapa sampel yang mewakili populasi.

\section{B. Uji Stasioner Data}

Berikut adalah definisi 1-2 terkait stasioneritas data (Seymour et al., 1997) :

\section{Definisi 1}

Misalkan $\left\{X_{t}\right\}$ adalah suatu time series stasioner. Fungsi autocovariance (PACF) dari $\left\{X_{t}\right\}$ pada lag $h$ adalah :

$$
\begin{aligned}
\gamma_{x}(h) & =\operatorname{cov}\left(X_{t+h}, X_{t}\right) \\
& =E\left[\left(X_{t+h}-\mu_{x}(t+h)\right)\left(X_{t}-\mu_{x}(t)\right)\right]
\end{aligned}
$$

\section{Definisi 2}

Misalkan $\left\{X_{t}\right\}$ adalah suatu time series stasioner. Fungsi autokorelasi (ACF) dari $\left\{X_{t}\right\}$ pada lag $h$ adalah

$$
\begin{aligned}
& \rho_{x}(h)=\operatorname{cor}\left(X_{t+h}, X_{t}\right) \\
= & \frac{\gamma_{x}(h)}{\gamma_{x}(0)}
\end{aligned}
$$

Uji ini dilakukan menggunakan correlogram didasarkan pada fungsi ACF dengan $\rho_{x}(h)$ dan $h(\mathrm{lag})$. Untuk data yang stationer, korelogram menurun dengan cepat menuju nol seiring dengan meningkatnya lag, sedangkan untuk data yang tidak stasioner, korelogram cenderung tidak menuju nol (turun lambat).

\section{Weighted Moving Average}

Weighted Moving Average

(WMA) adalah rata-rata bergerak yang memiliki bobot. Bobot ditentukan sedemikian rupa sehingga sehingga jumlah keseluruhan sama dengan satu. Misalnya untuk rata-rata bergerak 4 bulan, diberi bobot sebagai berikut : 0,4 ; 0,3; 0,2 dan 0,1 (Ardiana \& Loekito, 2018). Secara matematis perhitungan WMA dirumuskan dalam persamaan berikut (Heizer et al., 2017).

$$
w_{t} X_{t}+w_{t-1} X_{t-1}+\cdots
$$

$$
\begin{gathered}
F_{t+1}=\frac{+w_{t-m+1} X_{t-m+1}}{w_{t}+w_{t-1}+\cdots} \\
+w_{t-m+1}
\end{gathered}
$$

Keterangan:

$F_{t+1}$ : Data peramalan periode $t+1$

$X_{t} \quad$ : Data aktual untuk waktu $t$

$w_{t}$ : Bobot yang digunakan

$m$ : Jumlah periode untuk peramalan

\section{Single Exponential Smoothing}

Untuk menghitung ramalan dengan metode SES maka digunakan persamaan sebagai berikut (Eris et al., 2014) :

$$
F_{t+1}=\alpha X_{t}+(1-\alpha) F_{t}
$$

Keterangan :

$F_{t+1}$ : Data peramalan periode $t+1$

$F_{t} \quad$ : Data peramalan pada periode $t$

$X_{t} \quad$ : Data aktual pada periode ke $t$

$\alpha \quad$ : Bobot $(0<\alpha<1)$

\section{E. Ukuran Kesalahan Peramalan}

Keakuratan keseluruhan model peramalan WMA, SES, atau lainnyadapat ditentukan dengan membandingkan nilai peramalan dengan nilai aktual atau nilai yang diamati (Heizer et al., 2017) :

$$
e_{t}=X_{t}-F_{t}
$$

Keterangan :

$e_{t}$ : Error pada periode $t$

$X_{t}$ : Data aktual pada periode $t$

$F_{t}$ : Peramalan pada periode $t$ 
Berikut ini adalah ukuran kesalahan yang sering digunakan :

1. Mean Absolute Deviation (MAD)

Nilai ini dihitung dengan mengambil jumlah nilai absolut kesalahan peramalan individual (deviasi) dan membaginya dengan jumlah periode data $(n)$ :

MAD $=\frac{1}{n} \sum_{t=1}^{n}\left|e_{t}\right|$

Keterangan :

$e_{t}$ : Error pada periode $t$

$n$ : Banyaknya data

\section{Mean Squared Error (MSE)}

MSE adalah rata-rata perbedaan yang dikuadratkan diantara nilai yang diramalkan dengan yang diamati.

MSE $=\frac{1}{n} \sum_{t=1}^{n}\left(e_{t}^{2}\right)$

\section{Mean Absolute Percent Error (MAPE)}

Nilai ini dihitung sebagai ratarata perbedaan absolut antara nilai perkiraan dan nilai aktual, yang dinyatakan sebagai persentase dari nilai actual :

$$
\text { MAPE }=\frac{1}{n} \sum_{t=1}^{n} \frac{\left|e_{t}\right|}{X_{t}} \times 100 \%
$$

Nilai MAPE digunakan untuk mengetahui tingkat akurasi peramalan seperti yang ditunjukan pada Tabel dibawah ini :

Tabel 1. Akurasi Peramalan

\begin{tabular}{ll}
\hline NILAI MAPE & $\begin{array}{c}\text { AKURASI } \\
\text { PERAMALAN }\end{array}$ \\
\hline MAPE $\leq 10 \%$ & Tinggi \\
\hline $10 \%<$ MAPE $\leq 20 \%$ & Baik \\
$20 \%<$ MAPE $\leq 50 \%$ & Layak \\
\hline MAPE $>50 \%$ & Rendah \\
\hline
\end{tabular}

Berikut ini adalah beberapa hal yang dapat menyebabkan hasil WMA dan SES berbeda :
1) Data penelitian yang terlalu sedikit, sehingga tidak memenuhi syarat metode peramalan;

2) Kesalahan dalam pemilihan sampel;

3) Banyak data yang hilang atau tidak lengkap dan

4) Kesalahan pada Transformasi data.

\section{HASIL DAN PEMBAHASAN}

\section{A. Data APS Lima Kabupaten}

Data yang digunakan adalah data APS lima kabupaten yaitu Kabupaten Merauke, Jayawijaya, Jayapura, Biak Numfor dan Mimika tahun 2010 sampai dengan 2019 (BPS, 2019).

\section{B. Uji Stasioneritas}

Berikut grafik fungsi ACF menggunakan software Minitab 16 untuk kabupaten Merauke (Anim Ha) :

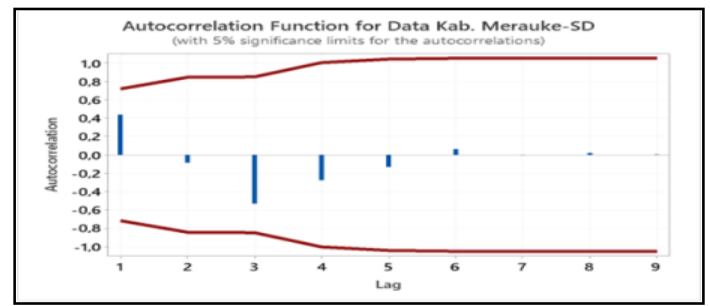

Gambar 1. ACF Merauke Jenjang SD

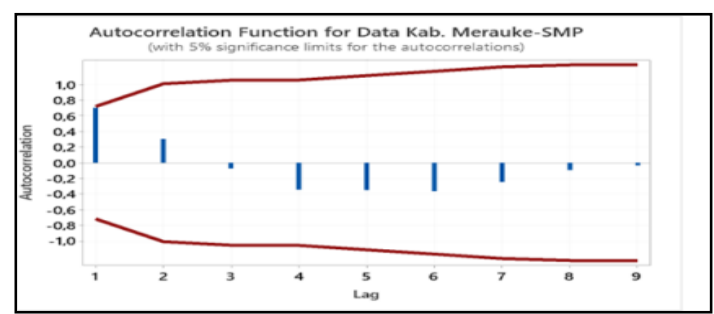

Gambar 2. ACF Merauke Jenjang SMP

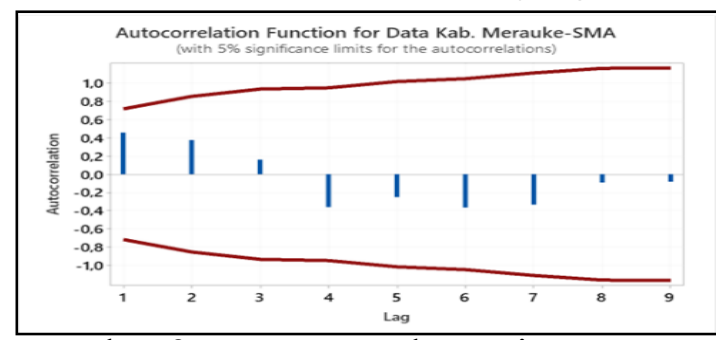

Gambar 3. ACF Merauke Jenjang SMA

Uji yang sama dilakukan juga untuk data APS Kabupaten Jayawijaya, Jayapura, Biak Numfor dan Mimika. 
Hasilnya akan terlihat bahwa data tersebut bersifat stasioner terhadap mean.

\section{Analisis APS dengan Metode WMA}

1. APS Merauke Jenjang SD

Setelah mempersiapkan data aktual, kemudian menghitung nilai peramalan WMA dengan periode 3 tahunan dengan menggunakan (pers. 1) menjadi :

$$
F_{3+1}=\frac{3 X_{3}+2 X_{2}+1 X_{1}}{3+2+1}
$$

Sehingga,

$$
\begin{aligned}
F_{2013} & =\frac{(3)(92,19)+(2)(94)}{3+(1)(97,8)} \\
& =\frac{276,57+188+97,8}{6} \\
& =\frac{562,37}{6} \\
& =93,728 \\
F_{2014} & =\frac{(2)(92,19)+(1)(94)}{3+2+1} \\
& =\frac{275,28+184,38+94}{6} \\
& =\frac{553,66}{6} \\
& =92,277
\end{aligned}
$$

2. Menghitung Nilai Error

Dari setiap data peramalan menggunakan (pers 3) sehingga :

$$
\begin{aligned}
e_{2013} & =91,76-93,728 \\
& =-1,968 \\
e_{2014} & =96,7-92,277 \\
& =4,423
\end{aligned}
$$

Untuk menghitung MAPE, maka perlu menghitung nilai persentase absolut dari setiap error.

$$
\begin{aligned}
& \text { tahun 2013 }=\frac{|-1,968|}{91,76} \times 100 \% \\
& \text { tahun } 2014=\frac{|4,423|}{96,7} \times 100 \%
\end{aligned}
$$

3. Menghitung MAPE (pers. 4) :

$$
\begin{aligned}
& \text { MAPE }=\frac{1}{7}(2,145 \%+4,574 \% \\
& +3,151 \%+2,777 \% \\
& +1,778 \%+1,095 \% \\
& +0,983 \% \text { ) } \\
& =\frac{1}{7}(16,504 \%) \\
& =2,358 \%
\end{aligned}
$$

Untuk jenjang Pendidikan SD, SMP, SMA Sederajat Kabupaten Merauke dilakukan seperti di atas untuk tahun 2013-2019. Perhitungan yang sama dilakukan juga untuk data APS Kabupaten Jayawijaya, Jayapura, Biak Numfor dan Mimika.

\section{Analisis APS dengan Metode SES}

1. APS Merauke Jenjang SD

Data peramalan pada tahun 2011 diasumsikan sama dengan data aktual pada tahun 2010 sehingga, $F_{2011}=97,8$.

Peramalan SES dengan menggunakan (pers. 2) sebagai berikut : Untuk $\alpha=0,1$ peramalannya,

$$
\begin{aligned}
& F_{2012}=(0,1)(94)+ \\
& (1-0,1)(97,8) \\
& =9,4+(0,9)(97,8) \\
& =9,4+88,02 \\
& =97,42
\end{aligned}
$$

Setelah hasil peramalan tahun 2011 dan 2012 diperoleh, untuk data selanjutnya lakukan cara yang sama hingga tahun 2019.

\section{Hitung Nilai Error}

Langkah selanjutnya menghitung nilai error dari setiap data peramalan menggunakan (pers 3) sehingga

$$
\begin{aligned}
e_{2011} & =94-97,8 \\
& =-3,8 \\
e_{2012} & =92,19-97,42 \\
& =-5,23
\end{aligned}
$$

Untuk menghitung MAPE maka perlu menghitung nilai persentase absolut dari setiap error.

$$
\begin{aligned}
\text { tahun } 2011 & =\frac{\mid-3,8]}{94} \times 100 \% \\
& =\frac{3,8}{94} \times 100 \%
\end{aligned}
$$




$$
\begin{aligned}
& =0,04043 \times 100 \% \\
& =4,043 \% \\
\text { tahun } 2012 & =\frac{\|-5,23]}{92,19} \times 100 \% \\
& =\frac{5,23}{92,19} \times 100 \% \\
& =0,05673 \times 100 \% \\
& =5,673 \%
\end{aligned}
$$

\section{Menghitung MAPE}

Dengan menggunakan (pers. 4) maka :

$$
\begin{aligned}
& M A P E=\frac{1}{9}( 4,043 \%+5,673 \% \\
&+5,598 \%+0,328 \% \\
&+0,981 \% \\
&+2,475 \%+0,431 \% \\
&+0,399 \% \\
&+0,882 \%) \\
&=\frac{1}{9}(20,81 \%) \\
&=2,312 \%
\end{aligned}
$$

Kemudian perhitungan yang sama dilakukan untuk tahun 2013-2019 dan perhitungan ini juga dilakukan untuk menentukan nilai MAPE. Selanjutnya dengan cara yang sama dihitung jenjang SMP, SMA dan sederajat, untuk peramalan data APS Kabupaten Jayawijaya, Jayapura, Biak Numfor, dan Mimika.

Perhitungan juga dilakukan untuk mencari nilai rata-rata APS lima wilayah adat tahun 2010-2019 jenjang SD, SMP dan SMA. Hasil perhitungan adalah sebagai berikut :

\section{Tabel 2. Rata-rata SD, SMP dan SMA}

\begin{tabular}{lccc}
\hline \multirow{2}{*}{ Kabupaten } & \multicolumn{3}{c}{ Jenjang Pendidikan } \\
\cline { 2 - 4 } & SD & SMP & SMA \\
\hline Merauke & 95,72 & 94,43 & 73,09 \\
\hline Jayawijaya & 86,57 & 80,89 & 62,91 \\
\hline Jayapura & 96,11 & 94,04 & 83,18 \\
\hline Biak Numfor & 95,96 & 96,35 & 83,07 \\
\hline Mimika & 95,61 & 91,61 & 69,86 \\
\hline
\end{tabular}

\section{E. Perbandingan WMA dan SES}

Perbandingan hasil peramalan menggunakan metode WMA dan SES untuk sampel data APS pada jenjang SD, SMP, SMA Sederajat dari lima kabupaten disajikan dalam Tabel 3-5.

Tabel 3. MAPE Jenjang SD Sederajat

\begin{tabular}{lcc}
\hline \multirow{2}{*}{ Kabupaten } & WMA & SES \\
\cline { 3 - 3 } & & $\mathrm{a}=0,1$ \\
\hline Merauke & $2,36 \%$ & $2,31 \%$ \\
\hline Jayawijaya & $4,71 \%$ & $6,31 \%$ \\
\hline Jayapura & $1,55 \%$ & $1,65 \%$ \\
\hline Biak Numfor & $2,00 \%$ & $2,26 \%$ \\
\hline Mimika & $3,12 \%$ & $2,97 \%$ \\
\hline
\end{tabular}

Tabel 4. MAPE Jenjang SMP Sederajat

\begin{tabular}{lcc}
\hline \multirow{2}{*}{ Kabupaten } & WMA & SES \\
\cline { 3 - 3 } & & $\mathrm{a}=0,1$ \\
\hline Merauke & $2,58 \%$ & $4,079 \%$ \\
\hline Jayawijaya & $5,55 \%$ & $9,596 \%$ \\
\hline Jayapura & $2,82 \%$ & $5,208 \%$ \\
\hline Biak Numfor & $2,24 \%$ & $3,856 \%$ \\
\hline Mimika & $4,04 \%$ & $5,560 \%$ \\
\hline
\end{tabular}

Tabel 5. MAPE Jenjang SMA Sederajat

\begin{tabular}{lcc}
\hline \multirow{2}{*}{ Kabupaten } & WMA & SES \\
\cline { 3 - 3 } & & $\mathrm{a}=0,1$ \\
\hline Merauke & $8,37 \%$ & $18,03 \%$ \\
\hline Jayawijaya & $12,03 \%$ & $28,55 \%$ \\
\hline Jayapura & $4,57 \%$ & $9,32 \%$ \\
\hline Biak Numfor & $6,12 \%$ & $8,93 \%$ \\
\hline Mimika & $11,35 \%$ & $25,68 \%$ \\
\hline
\end{tabular}

Berdasarkan tabel 3-5 di atas, beberapa hal dapat dijelaskan sebagai berikut :

1. Peramalan data APS pada jenjang SD menunjukkan bahwa Kabupaten Jayawijaya, Kabupaten Jayapura dan Kabupaten Biak Numfor memiliki nilai MAPE terkecil menggunakan metode WMA. Untuk Kabupaten 
Merauke dan Mimika memiliki nilai MAPE terkecil menggunakan metode SES.

2. Peramalan data APS pada jenjang SMP menunjukkan bahwa Kabupaten Merauke, Jayawijaya, Jayapura, Biak Numfor dan Mimika memiliki nilai MAPE terkecil menggunakan metode WMA.

3. Peramalan data APS pada jenjang SMA menunjukkan bahwa Kabupaten Merauke, Jayawijaya, Jayapura, Biak Numfor dan Mimika memiliki nilai MAPE terkecil menggunakan metode WMA.

\section{KESIMPULAN}

Berdasarkan nilai MAPE yang diperoleh metode WMA dan SES $(\alpha=0.1)$ terlihat bahwa metode dengan akurasi kesalahan terkecil adalah WMA. Artinya WMA merupakan metode terbaik dalam peramalan data APS yang berfluktuasi, karena lebih dominan. Hasil analisis pada tabel 2 juga menunjukan bahwa, data berfluktuasi dari tahun 2010-2019. Rata-rata APS lima wilayah adat dari tahun 2010-2019 untuk jenjang SD Kabupaten Jayapura memiliki APS yang lebih tinggi. Untuk Jenjang SMP Biak Numfor dan untuk jejang SMA Kabupaten Jayapura. Sehingga WMA dapat menjadi metode rujukan untuk peramalan APS ditahun yang akan datang. Diharapkan penelitian selanjutnya untuk data APS dapat dianalisis menggunakan metode peramalan dengan pola data random yang lain. Apabila para peneliti menggunakan data yang lebih banyak serta variabel yang lebih kompleks, maka diperlukan tambahan aplikasi seperti seperti: Matlab dan POM QM.

\section{Ucapan Terima Kasih}

Ucapan terima kasih disampaikan kepada Kementerian Pendidikan dan Kebudayaan, melalui Hibah Penelitian PNBP (Penerimaan Negara Bukan Pajak) tahun anggaran 2021, pada Fakultas MIPA Universitas Cenderawasih.

\section{DAFTAR PUSTAKA}

Ardiana, D. P. Y., \& Loekito, L. H. (2018). Sistem Informasi Peramalan Persediaan Barang Menggunakan Metode Weighted Moving Average. Jurnal Teknologi Informasi Dan Komputer. https://doi.org/10.36002/jutik.v4i1.3 97

Arnita, A. (2020). Comparison of Single Exponential Smoothing, Naive Model, and SARIMA Methods for Forecasting Rainfall in Medan. Jurnal Matematika, Statistika Dan Komputasi.

https://doi.org/10.20956/jmsk.v17i1. 10236

Asynari, E., Wahyudi, D., \& Aeni, Q. (2020). Analisis Peramalan Permintaan Pada Geprek Bensu Menggunakan Metode Time Series. Teknologi Dan Sistem Informasi.

Badan Pusat Statistik (BPS). (2019). Provinsi Papua Dalam Angka Tahun 2019.

https://papua.bps.go.id/indicator/28/1 40/1/angka-partisipasi-sekolah-aps.html

Eris, P. N., Nohe, D. A., \& Wahyuningsih, S. (2014). Peramalan Dengan Metode Smoothing dan Verifikasi Metode Peramalan Dengan Grafik Pengendali Moving Range (MR) (Studi Kasus: Produksi Air Bersih di PDAM Tirta Kencana Samarinda). Jurnal EKSPONENSIAL, 5(1), 203-210.

Heizer, J., Render, B., \& Munson, C. (2017). Operations Management: Sustainability \& Supply Chain 
Management 12th edition. In Corporate finance.

Hudaningsih, N., Firda Utami, S., \& Abdul Jabbar, W. A. (2020). PERBANDINGAN PERAMALAN PENJUALAN PRODUK AKNIL PT.SUNTHI SEPURI MENGGUANAKAN METODE SINGLE MOVING AVERAGE DAN SINGLE EXPONENTIAL SMOOTHING. Jurnal Informatika, Teknologi Dan Sains. https://doi.org/10.51401/jinteks.v2i1 .554

Karini, P. (2018). Pengaruh Tingkat Kemiskinan Terhadap Angka Partisipasi Sekolah Usia 16-18 Tahun di Provinsi Kepulauan Bangka Belitung. Al-Ishlah: Jurnal Pendidikan.

Nurhanifa, N., \& Pujiastuti, H. (2020). Prediksi Angka Partisipasi Sekolah (APS) di Provinsi Banten dengan Menggunakan Interpolasi Lagrange. Sainmatika: Jurnal Ilmiah Matematika Dan Ilmu Pengetahuan Alam.

https://doi.org/10.31851/sainmatika. v17i1.3822

Puti Yasmin, (2021). Riset: Angka Partisipasi Sekolah di RI dari PAUD Sampai Kuliah Turun. https://www.detik.com/edu/sekolah/ d-5644851/riset-angka-partisipasisekolah-di-ri-dari-paud-sampaikuliah-turun.

Rachman, R. (2018). Penerapan Metode Moving Average Dan Exponential Smoothing Pada Peramalan Produksi Industri Garment. Jurnal Informatika.

https://doi.org/10.31311/ji.v5i2.3309
Rahmatin, U. Z., \& Soejoto, P. D. . A. (2017). Pengaruh Tingkat Kemiskinan Dan Jumlah Sekolah Terhadap Angka Partisipasi Sekolah (Aps) Di Kota Surabaya. Jurnal Pendidikan Ekonomi.

Rais, A. N., Rousyati, R., Thira, I. J., Kholifah, D. N., Purwati, N., Kristania, Y. M., \& Kristania, Y. M. (2020). Evaluasi Metode Forecasting pada Data Kunjungan Wisatawan Mancanegara ke Indonesia. EVOLUSI : Jurnal Sains Dan Manajemen. https://doi.org/10.31294/evolusi.v8i 2.8971

Seymour, L., Brockwell, P. J., \& Davis, R. A. (1997). Introduction to Time Series and Forecasting. Journal of the American Statistical Association. https://doi.org/10.2307/2965440

Wahyuni, N. N. S., Candiasa, I. M., \& Juniantari, M. (2020). Prediksi Angka Partisipasi Sekolah Menurut Kelompok Umur Di Provinsi Bali Menggunakan Single Moving Average. Maju, 7(2), 101.

Yolanda, S. (2019). Transformasi Berkelanjutan Berbasis Sumber Daya Lokal: Sebuah Refleksi Penelitian Aksi Partisipatif terhadap Perempuan di Akar Rumput, Papua dan Papua Barat. Jurnal Inada: Kajian Perempuan Indonesia Di Daerah Tertinggal, Terdepan, Dan Terluar. https://doi.org/10.33541/ji.v1i2.899

Yudiarti, \& Wira, W. (2019). Perbandingan Metode Peramalan Penjualan Semen Menggunakan Moving Average Dan Single Exponential Smoothing. Jurnal Ilmiah Matematika. 